\title{
Comparison of Different Fuzzy AHP Methodologies in Risk Assessment
}

\author{
Andrejs Radionovs, Oleg Uzhga-Rebrov \\ Rezekne Academy of Technologies
}

\begin{abstract}
Being able to evaluate risks is an important task in many areas of human activity: economics, ecology, etc. Usually, environmental risk assessment is carried out on the basis of multiple and sometimes conflicting factors. Using multiple criteria decision-making (MCDM) methodology is one of the possible ways to solve the problem. Methodologies of analytic hierarchy process (AHP) are the most commonly used MCDM methods, which combine subjective and personal preferences in risk assessment process. However, AHP involves human subjectivity, which introduces vagueness type of uncertainty and requires the usage of decision making under those uncertainties. In this paper it was considered to deal with uncertainty by using the fuzzy-based techniques. However, nowadays there exist multiple Fuzzy AHP methodologies developed by different authors. In this paper, these Fuzzy AHP methodologies will be compared, and the most appropriate Fuzzy AHP methodology for the application in case of environmental risks assessment will be offered on the basis of this comparison.
\end{abstract}

Keywords: fuzzy logic, risk assessment, fuzzy representation of knowledge, fuzzy analytical hierarchy process.

\section{INTRODUCTION}

Risks analysis is an integral part of the ecological risks management.

Usually the process of risks assessment includes objective data; however, the management of risks considers preferences and relations having both objective and subjective elements [1]. The risk management considers tasks of taking decisions, which includes the problem of choosing alternatives on the basis of numerous and sometimes conflicting factors. One of the possibilities of solving this problem is using a Multiple Criteria Decision-Making (MCDM) methodology. One of popular methods of the MCDM group is Analytic Hierarchy Process (AHP), which had been worked out and firstly published in papers [2] [3].

However, the AHP methodology is connected with human judgements and subjective opinions, which make the processes of taking decisions uncertain. In order to solve the problem a Fuzzy Analytic Hierarchy Process (FAHP) methodology can be used.

The main aim of this article is to investigate various FAHP methods, as well as to produce the risk analysis on the basis of one of the methods ranking the risk factors by their negative impact on ecology.

\section{ANALYTIC HIERARCHY PROCESS}

Analytic Hierarchy Process (AHP) was firstly offered in 1970s by American specialist in the sphere of operative analysis T.L. Saaty [4].

AHP method uses special mathematical methods for processing subjective preferences of person or group of experts of certain field on the basis of relevant factors while evaluating and analysing decisions. AHP method is based on precondition that the process of taking a global decision in complicated task, but it can be solved by dividing and structuring the complicated task into numerous simple tasks, illustrating them in a form of a clear hierarchical structure.

In the risk analysis AHP method may be described by 3 main stages: 1) creation of a hierarchical model of the risk factors; 2) calculation of weight of the risk factors; 3) a quantitative assessment of the risk level. As a result, for each risk level resulting assessment is calculated. The risks analysis is implemented on the basis of comparison of these assessments.

Currently there exist a number of researches aligning AHP methodology and the mechanism of fuzzy logic. Fuzzy logic methodology is being used with analytic hierarchy process to form a model for risk assessment. These methods of risk assessment are widely used in various fields, for example the risk assessment of floor water invasion in coal mines [5].

In majority of cases the fuzzy AHP method assumes that each risk factor is illustrated as an element of lower level of hierarchical structure and is expressed by fuzzy number, which represents a combination of the fuzzy assessment of possibility of a corresponding unfavourable event and of the fuzzy assessment of possible losses connected with the realization of this event.

In this paper three the most frequently used and the most popular FAHP methods will be analysed. 
These are: the van Laarhoven and Pedrycz, Buckley, Chang FAHP methods. While analysing these FAHP methods, it is possible to conclude that the main methodology and the action model may be formulated as a six-step sequence and is illustrated schematically in Fig. 1. Main differences for each method are represented by stages "Weight calculation for risk factors" and "Individual preferences aggregation". These differences, as well as the main characteristics, advantages and disadvantages of methods in total will be investigated further in the article.

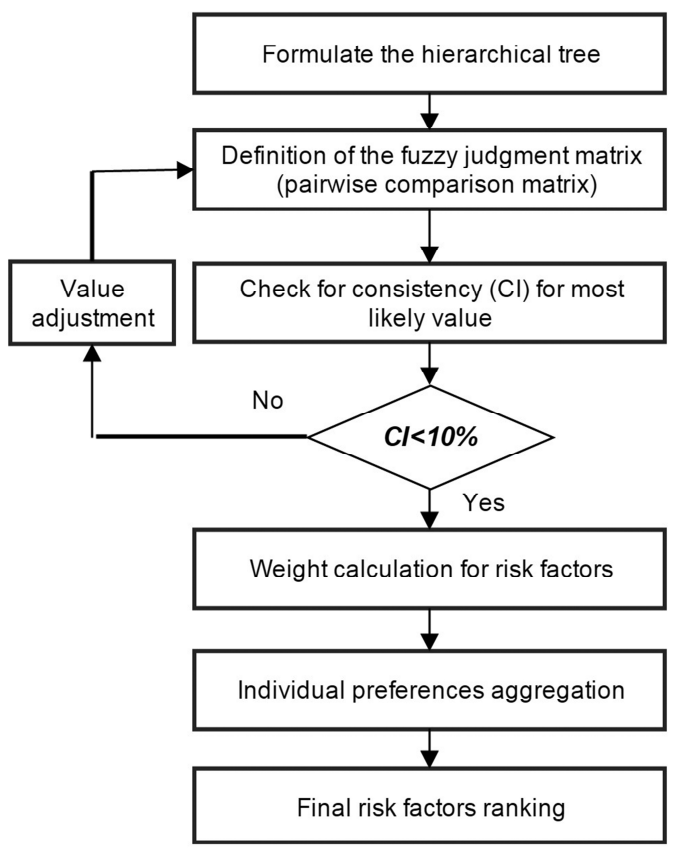

Fig. 1. Fuzzy analytic hierarchy process.

\section{THE VAN LAARHOVEN AND PEDRYCZ METHOD}

FAHP method was firstly offered in 1983 by van Laarhoven and Pedrycz. The main advantages of this FAHP method are the following:

1) The method is an extension of the Saaty AHP method, where instead of numerical assessment the triangular fuzzy numbers (TFN) are used in order to widen the standard AHP methodology.

2) The method supports the analysis and processing of assessments by numerous experts. It is reached by averaging the assessments of numerous experts in cells of matrix of pairwise assessments, arithmetic or geometric means may be used for this purpose, too.

3) Lootsma's logarithmic least square method is used to derive the fuzzy weight and fuzzy performance scores.

4) Approximate fuzzy multiplication is used in comparison of factors.

In accordance with [5] the offered by van Laarhoven and Pedrycz common structure of matrix for comparison of criteria (factors) looks as follows:

$$
\tilde{\mathrm{C}}=\left(\tilde{\mathrm{c}}_{\mathrm{ij}}\right)_{\mathrm{K} \times \mathrm{K}}=\left(\begin{array}{cccc}
(1,1,1) & \tilde{\tilde{\mathrm{c}}}_{12} & \ldots & \underline{\tilde{\mathrm{c}}}_{1 \mathrm{~K}} \\
\tilde{\tilde{\mathrm{c}}}_{21} & (1,1,1) & \ldots & \underline{\tilde{\mathrm{c}}}_{2 \mathrm{~K}} \\
\vdots & \vdots & \ddots & \vdots \\
\tilde{\tilde{\mathrm{c}}}_{\mathrm{K} 1} & \tilde{\tilde{\mathrm{c}}}_{\mathrm{K} 2} & \cdots & (1,1,1)
\end{array}\right)
$$

where

$$
\begin{aligned}
& \left.\tilde{\mathrm{c}}_{\mathrm{ij}}=\left(\tilde{\mathrm{c}}_{\mathrm{ij} 1}, \cdots, \tilde{\mathrm{c}}_{\mathrm{ijn}}\right)^{\mathrm{T}}\right)^{\mathrm{c}} \\
& \tilde{\mathrm{c}}_{\mathrm{ijt}}=\left(1_{\mathrm{ijt}}, \mathrm{m}_{\mathrm{ijt}}, \mathrm{u}_{\mathrm{ijt}}\right)=\tilde{\mathrm{c}}_{\mathrm{jit}}^{-1}=\left(\frac{1}{\mathrm{u}_{\mathrm{jit}}}, \frac{1}{\mathrm{~m}_{\mathrm{jit}}}, \frac{1}{1_{\mathrm{jit}}}\right) \\
& \mathrm{i}, \mathrm{j}=1,2, \ldots, \mathrm{K}, \mathrm{i} \neq \mathrm{j}, \quad \mathrm{t}=0, \ldots, \mathrm{n}_{\mathrm{ij} .}
\end{aligned}
$$

In (2) meaning $\mathrm{n}_{\mathrm{ij}}=0$ denotes an empty cell or the lack of comparison, however $n_{i j}>1$ in its turn implies a cell with numerous comparisons of factors provided by some experts. Therefore, for fuzzy weight vector (w), the fuzzy logarithmic least squares model is to be minimized using equation (3)

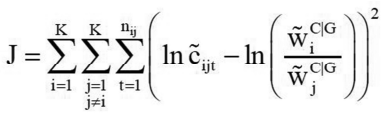

$$
\begin{aligned}
& \begin{aligned}
=\sum_{\mathrm{i}=1}^{\mathrm{K}} \sum_{\substack{\mathrm{j}=1 \\
\mathrm{j} \neq \mathrm{i}}}^{\mathrm{K}} \sum_{\mathrm{t}=1}^{\mathrm{n}_{\mathrm{ij}}}\left(\left(\ln \mathrm{c}_{\mathrm{ijt}}^{\mathrm{L}}-\ln \mathrm{w}_{\mathrm{i}}^{\mathrm{L}}+\ln \mathrm{w}_{\mathrm{j}}^{\mathrm{U}}\right)^{2}+\left(\ln \mathrm{c}_{\mathrm{ijt}}^{\mathrm{M}}-\ln \mathrm{w}_{\mathrm{i}}^{\mathrm{M}}+\ln \mathrm{w}_{\mathrm{j}}^{\mathrm{M}}\right)^{2}+\right. \\
\left.+\left(\ln \mathrm{c}_{\mathrm{ijt}}^{\mathrm{U}}-\ln \mathrm{w}_{\mathrm{i}}^{\mathrm{U}}+\ln \mathrm{w}_{\mathrm{j}}^{\mathrm{L}}\right)^{2}\right)
\end{aligned}
\end{aligned}
$$

In (3) $\mathrm{L}$ and $\mathrm{U}$ parameters(indexes) represent a lower and a higher boarder of triangular fuzzy numbers respectively and $M$ parameter denotes the mode. More detailed justification of the formula can be found in the papers [6] and [7].

Setting of $\mathrm{l}_{\mathrm{i}}=\ln \mathrm{w}^{\mathrm{L}}, \mathrm{m}_{\mathrm{i}}=\ln \mathrm{w}^{\mathrm{M}}, \mathrm{u}_{\mathrm{i}}=\ln \mathrm{w}^{\mathrm{U}}$, van Laarhoven and Pedrycz got the normalized result as equation (4), which they used as an estimate for $\mathrm{w}_{\mathrm{i}}-\mathrm{a}$ local weight vector.

$$
\left(\frac{\exp \left(\mathrm{l}_{\mathrm{i}}\right)}{\sum_{\mathrm{i}=1}^{\mathrm{K}} \exp \left(\mathrm{u}_{\mathrm{i}}\right)}, \frac{\exp \left(\mathrm{m}_{\mathrm{i}}\right)}{\sum_{\mathrm{i}=1}^{\mathrm{K}} \exp \left(\mathrm{m}_{\mathrm{i}}\right)}, \frac{\exp \left(\mathrm{u}_{\mathrm{i}}\right)}{\sum_{\mathrm{i}=1}^{\mathrm{K}} \exp \left(\mathrm{l}_{\mathrm{i}}\right)}\right), \quad \mathrm{i}=1, \ldots, \mathrm{K},
$$

In order to calculate a global weight vector van Laarhoven and Pedrycz alternatively offered to use an equation, where a value is calculated through the aggregation of local weights.

$$
\left(\mathrm{l}_{1}, \mathrm{~m}_{1}, \mathrm{u}_{1}\right) \otimes\left(\mathrm{l}_{2}, \mathrm{~m}_{2}, \mathrm{u}_{2}\right) \sim\left(\mathrm{l}_{1} \mathrm{l}_{2}, \mathrm{~m}_{1} \mathrm{~m}_{2}, \mathrm{u}_{1} \mathrm{u}_{2}\right)
$$

After the analysis of this method it is possible to distinguish one advantage comparing it to others: the options of multiple experts can be modelled in the reciprocal matrix.

Despite the characteristics of the van Laarhoven and Pedrycz FAHP method, in accordance with article [7] it has some significant disadvantages, too:

1) The equation (5), calculates the triangular fuzzy numbers only approximately, therefore there may occur serious uncertainties under certain conditions; 
2) Not always there exists a solution for lineal equations used in the calculation of the weights vector.

3) In one comparison changing of priorities (in one direction) may cause a reverse of range in replication of the existing values.

4) Difficulties in calculation of equation (4), which is used to normalize local fuzzy weights. Therefore, for solving even a small task a lot of calculation expenses will be needed.

5) Uncertainty of local fuzzy weights at incomplete matrix of fuzzy comparisons.

\section{THE BUCKLEY METHOD}

The FAHP method by J.J. Buckley [8] stands next in the chronological list. Its main idea, in comparison with Laarhoven and Pedrycz FAHP method, was to substitute the fuzzy ratios into the solution of the normal equations. Also, in order to get fuzzy weights J. J. Buckley offered to use geometric mean, as he wanted to use the method, which would be easy to widen into fuzzy inverse matrix. [8]

The main characteristics of the Buckley FAHP method are the following.

1) Similarly to the van Laarhoven and Pedrycz, the Buckley FAHP method is an extension of the Saaty AHP method where instead of numerical assessment the trapezoidal fuzzy numbers are used in order to widen AHP method.

2) The geometric mean method is used for analysis and calculation of the resulting vector in the factors comparison.

3) For matrix of comparison in equation (1), the geometric mean procedure takes the form of (6), and therefore the local weights are calculated by (7).

4)

$$
\begin{aligned}
& \tilde{\mathrm{r}}_{\mathrm{i}}=\left(\tilde{\mathrm{c}}_{\mathrm{i} 1} \otimes \cdots \otimes \tilde{\mathrm{c}}_{\mathrm{iK}}\right)^{1 / \mathrm{K}}, \mathrm{i}=1, \ldots, \mathrm{K} \\
& \tilde{\mathrm{w}}_{\mathrm{i}}=\tilde{\mathrm{r}}_{\mathrm{i}} \otimes\left(\tilde{\mathrm{r}}_{1} \oplus \cdots \oplus \tilde{\mathrm{r}}_{\mathrm{K}}\right)^{-1}, \mathrm{i}=1, \ldots, \mathrm{K}
\end{aligned}
$$

At the end, the equation (8) is used to calculate the final resulting vector.

$$
\tilde{\mathrm{w}}_{\mathrm{i}}^{\mathrm{A} \mid \mathrm{G}}=\left(\tilde{\mathrm{w}}_{\mathrm{i}}^{\mathrm{A} \mid \mathrm{C}_{1}} \otimes \tilde{\mathrm{w}}_{1}^{\mathrm{C} \mid \mathrm{G}}\right) \oplus \cdots \oplus\left(\tilde{\mathrm{w}}_{\mathrm{i}}^{\mathrm{A} \mid \mathrm{C}_{\mathrm{K}}} \otimes \tilde{\mathrm{w}}_{\mathrm{K}}^{\mathrm{Cl} G}\right)
$$

More detailed description of the method is available in paper [9]. After having analysed the method, it is possible to distinguish some its advantages:

1) It is easy to extend to the fuzzy case in the Buckley FAHP method.

2) It guarantees a unique solution to the reciprocal comparison matrix.

Despite the characteristics and advantages of the offered Buckley FAHP method, in accordance with research [10], it has got disadvantages, too:
1) If there is not a perfect consistency, the geometric row procedure can give different weights compared to the eigenvector method.

2) High computational requirements.

$$
\text { V.THE CHANG METHOD }
$$

Next in the chronological list stands the D. Chang FAHP method [11]. Here are the main characteristics of this FAHP method:

1) Triangular fuzzy numbers are used instead of numerical assessment in order to widen AHP method.

2) Arithmetic mean is used for determining the priority vector of factors.

3) Final ranking of results is implemented on the basis of numerical values.

D. Chang used a Fuzzy Extent Analysis for comparison of matrices, elements of which were represented by triangular fuzzy numbers. Applying this theory in fuzzy comparison matrix, one can calculate the value of fuzzy synthetic extent with respect to the i-th object as follows:

$$
S_{i}=\sum_{j=1}^{k} \tilde{c}_{i j} \otimes\left[\sum_{k=1}^{k} \sum_{j=1}^{k} \tilde{c}_{k j}\right]^{-1}
$$

where

$$
\sum_{j=1}^{k} \widetilde{c}_{i j}=\left(\sum_{j=1}^{k} l_{j}, \sum_{j=1}^{k} m_{j}, \sum_{j=1}^{k} u_{j}\right)
$$

and

$$
\left[\sum_{i=1}^{k} \sum_{j=1}^{k} \tilde{c}_{i j}\right]^{-1}=\left(\frac{1}{\sum_{j=1}^{k} u_{j}}, \frac{1}{\sum_{j=1}^{k} m_{j}}, \frac{1}{\sum_{j=1}^{k} l_{j}}\right)
$$

The normalized row sums $S_{\mathrm{i}}$ are then compared using the degree of possibility values using (12)

$$
\begin{aligned}
& V\left(\tilde{\mathrm{S}}_{\mathrm{i}} \geq \tilde{\mathrm{S}}_{\mathrm{j}}\right)= \\
& \begin{cases}1, & \text { if } m_{\mathrm{i}} \geq m_{\mathrm{j}} \\
0, & \text { if } l_{\mathrm{j}} \geq u_{\mathrm{i}} \\
\frac{l_{\mathrm{j}}-u_{\mathrm{i}}}{\left(m_{\mathrm{i}}-u_{\mathrm{i}}\right)-\left(m_{\mathrm{j}}-l_{\mathrm{j}}\right)}, & \text { otherwise }\end{cases}
\end{aligned}
$$

D. Chang offered to use equation (13) for calculating the global weight vector.

$w_{i}=\frac{V\left(\tilde{S}_{i} \geq \tilde{S}_{j} \mid j=1,2, \ldots, K, j \neq i\right)}{\sum_{k=1}^{K} V\left(\tilde{S}_{k} \geq \tilde{S}_{j} \mid j=1,2, \ldots, K, j \neq k\right)}, i=1,2, \ldots, K_{(13)}$

Despite the characteristics and advantages of the offered Chang FAHP method, it has got a disadvantage: instead of numerical assessments the method may use only triangular fuzzy numbers.

In accordance with article [12], despite possible limitations, the offered by Chang method includes the best elements of other methods, analysed in this paper. This fact is substituted also by a number of other papers, where the method is used in the analysis 
and ranging of the risk factors, e.g. [13], [14]. A relatively low number of computational requirements is also an advantage of the method.

After having analysed the characteristics, positive and negative aspects of the methods mentioned in this paper, it is possible to conclude that the best methods for the risk assessment are the Buckley and the Chang methods.

The usage of the Chang method for the risk analysis ranking the risk factors by their negative ecological impacts is described further in the paper.

\section{CASE STUDY}

The FAHP methodology for the risk factors assessment and ranking in the present paper is based on the Chang method is defined as the sequence of six steps and is presented in Fig. 1. Let's look through each of these steps in details.

A.Step 1: Formulate the hierarchical tree.

Identification of the risk factors is the first step in the ecological risk assessment.

In compliance with peculiarities of the ecological risk analysis and with the Chang method, on the basis of experts' experience, there were compiled 12 factors influencing the level of the ecological risks referring to the spread of invasive species. Also, in accordance with the FAHP methodology, the risk factors have been grouped into 4 categories. All factors and categories are illustrated in Fig. 2, where the categories of factors are marked as $F=\{F 1, F 2, F 3$, $\mathrm{F} 4\}$, but the factors themselves as $\mathrm{f}_{\mathrm{i}}, \mathrm{F}_{\mathrm{i}}=\left\{\mathrm{f}_{\mathrm{ij}}\right\}, \mathrm{i}=$ $1, \ldots, 4, \mathrm{j}=1,2,3$.

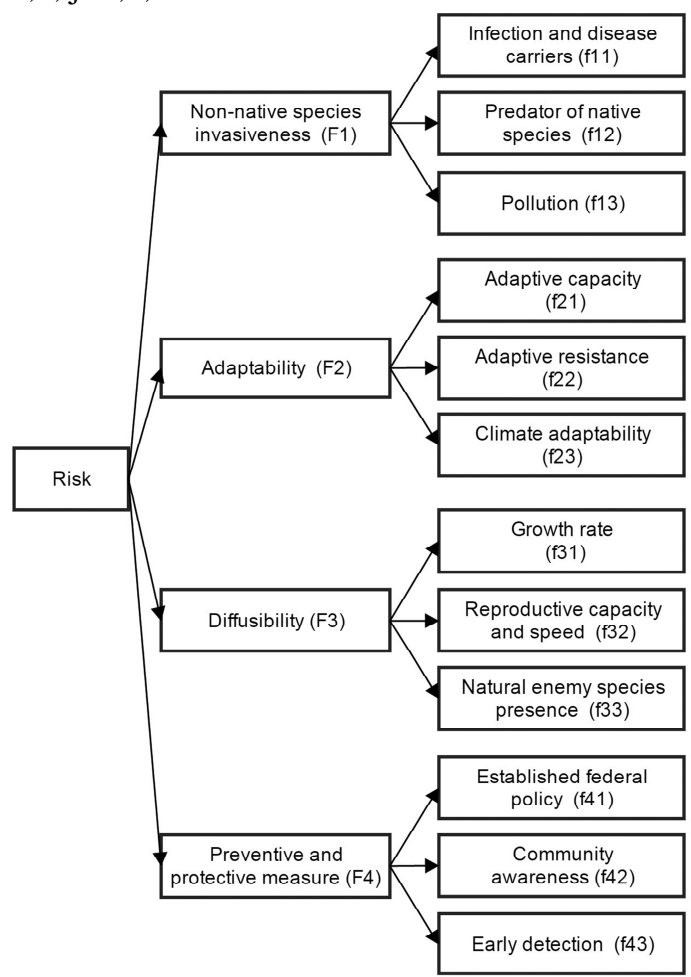

Fig. 2. The hierarchy of the risk factors influencing the level of the ecological risks referring to the spread of invasive species.
B. Step 2: Definition of the fuzzy judgment matrix.

The second step of the Chang FAHP method includes a pairwise comparison of factors in compliance with hierarchical structure illustrated in Fig. 2. The results of the comparison are represented by the judgement Tables II, III, IV, V and VI. Table I includes fuzzy values of a common scale, where each result of comparison is represented by a triangular fuzzy number and its backward equivalent.

Table I

Linguistic Scale For Relative Importance

\begin{tabular}{|l|c|c|}
\hline $\begin{array}{c}\text { Linguistic scale for } \\
\text { relative importance }\end{array}$ & $\begin{array}{c}\text { Triangular } \\
\text { fuzzy scale }\end{array}$ & $\begin{array}{c}\text { Reciprocal of } \\
\text { triangular } \\
\text { fuzzy scale }\end{array}$ \\
\hline Exactly the same & $(1,1,1)$ & $(1,1,1)$ \\
\hline Same importance & $(1 / 2,1,3 / 2)$ & $(2 / 3,1,2)$ \\
\hline Slightly important & $(1,3 / 2,2)$ & $(1 / 2,2 / 3,1)$ \\
\hline Serious importance & $(3 / 2,2,5 / 2)$ & $(2 / 5,1 / 2,2 / 3)$ \\
\hline More serious importance & $(2,5 / 2,3)$ & $(1 / 3,2 / 5,1 / 2)$ \\
\hline Absolute importance & $(5 / 2,3,7 / 2)$ & $(2 / 7,1 / 3,2 / 5)$ \\
\hline
\end{tabular}

Table II

Judgment Matrix For Risk Categories

\begin{tabular}{|c|c|c|c|c|}
\hline$F$ & $F_{1}$ & $F_{2}$ & $F_{3}$ & $F_{4}$ \\
\hline$F_{1}$ & $(1,1,1)$ & $(1 / 2,2 / 3,1)$ & $(2 / 3,1,2)$ & $(1 / 3,2 / 5,1 / 2)$ \\
\hline$F_{2}$ & $(1,3 / 2,2)$ & $(1,1,1)$ & $(1,3 / 2,2)$ & $(1,3 / 2,2)$ \\
\hline$F_{3}$ & $(1 / 2,1,3 / 2)$ & $(1 / 2,2 / 3,1)$ & $(1,1,1)$ & $(3 / 2,2,5 / 2)$ \\
\hline$F_{4}$ & $(2,5 / 2,3)$ & $(1 / 2,2 / 3,1)$ & $(2 / 5,1 / 2,2 / 3)$ & $(1,1,1)$ \\
\hline
\end{tabular}

Table III

Judgment Matrix For Risk Category- Non-Native Species Invasiveness

\begin{tabular}{|c|c|c|c|}
\hline$F_{1}$ & $f_{l 1}$ & $f_{l 2}$ & $f_{l 3}$ \\
\hline$f_{l 1}$ & $(1,1,1)$ & $(1 / 2,2 / 3,1)$ & $(1,3 / 2,2)$ \\
\hline$f_{l 2}$ & $(1,3 / 2,2)$ & $(1,1,1)$ & $(1,3 / 2,2)$ \\
\hline$f_{l 3}$ & $(1 / 2,2 / 3,1)$ & $(1 / 2,2 / 3,1)$ & $(1,1,1)$ \\
\hline
\end{tabular}

Table IV

Judgment Matrix For Risk Category - ADAPTABILITY

\begin{tabular}{|c|c|c|c|}
\hline$F_{2}$ & $f_{21}$ & $f_{22}$ & $f_{23}$ \\
\hline$f_{21}$ & $(1,1,1)$ & $(2 / 3,1,2)$ & $(1,3 / 2,2)$ \\
\hline$f_{22}$ & $(1 / 2,1,3 / 2)$ & $(1,1,1)$ & $(1 / 2,2 / 3,1)$ \\
\hline$f_{23}$ & $(1 / 2,2 / 3,1)$ & $(1,3 / 2,2)$ & $(1,1,1)$ \\
\hline
\end{tabular}

Table V

Judgment Matrix For Risk Category - Diffusibility

\begin{tabular}{|c|c|c|c|}
\hline$F_{3}$ & $f_{31}$ & $f_{32}$ & $f_{33}$ \\
\hline$f_{31}$ & $(1,1,1)$ & $(1 / 2,2 / 3,1)$ & $(1 / 2,2 / 3,1)$ \\
\hline$f_{32}$ & $(1,3 / 2,2)$ & $(1,1,1)$ & $(1 / 2,2 / 3,1)$ \\
\hline$f_{33}$ & $(1,3 / 2,2)$ & $(1,3 / 2,2)$ & $(1,1,1)$ \\
\hline
\end{tabular}


Environment. Technology. Resources, Rezekne, Latvia Proceedings of the $11^{\text {th }}$ International Scientific and Practical Conference. Volume II, 137-142

Table VI

Judgment Matrix For Risk Category - Preventive And Protective Measures

\begin{tabular}{|c|c|c|c|}
\hline$F_{4}$ & $f_{41}$ & $f_{42}$ & $f_{43}$ \\
\hline$f_{41}$ & $(1,1,1)$ & $(1,3 / 2,2)$ & $(1,3 / 2,2)$ \\
\hline$f_{42}$ & $(1 / 2,2 / 3,1)$ & $(1,1,1)$ & $(1,3 / 2,2)$ \\
\hline$f_{43}$ & $(1 / 2,2 / 3,1)$ & $(1 / 2,2 / 3,1)$ & $(1,1,1)$ \\
\hline
\end{tabular}

C. Step 3: Consistency test.

Consistency plays a big role in human thinking processes, it is important to ensure a consistency in pairwise comparisons of factors, too. It is significant because the results of pairwise comparisons may occur to be not consistent or correct due to unclear experts' judgements. Therefore, the third step in the Chang FAHP method is the check-up of the consistency of experts' judgements. For the check-up of consistency Chang used the same method as it was offered in papers [2] and [3] devoted to the T.L. Saaty for APH method. The main idea for testing the consistency is the calculation of maximum eigenvalue, values of which are further used in calculation of Consistency Index (CI). Consistency Index indicates whether expert provided the consistent values comparisons in a set of evaluations is calculated by equation (14).

$$
C I=\frac{\lambda_{\max }-n}{n-1}
$$

The final possible consistency of results of pairwise comparisons is determined by the consistency ratio $\mathrm{CR}=\mathrm{CI} / \mathrm{RI}$, where $\mathrm{RI}$ is a random index got by averaging the $\mathrm{CI}$ of a randomly generated reciprocal matrix [3]. RI values for matrices of different dimensions (n) are presented in Table VII. In accordance with [3]: a maximally permissible value of the consistency ratio is $10 \%$. In case if the consistency ratio exceeds the value, analysis should be interrupted and the results of pairwise comparisons returned to experts for determining and preventing the inconsistency.

Table VII

Random Indexes for N Dimensional Matrix [3]

\begin{tabular}{|c|c|c|c|c|c|c|c|}
\hline $\mathrm{n}$ & 1 & 2 & 3 & 4 & 5 & 6 & $\ldots$ \\
\hline $\mathrm{RI}$ & 0 & 0 & 0.52 & 0.89 & 1.11 & 1.25 & $\ldots$ \\
\hline
\end{tabular}

Results of calculations of consistency of pairwise comparisons represented in Table II are included into Table VIII.

As it is seen in the Table VIII, all values of the consistency ratio (CR) do not exceed the allowed value; therefore, the results of matrix of pairwise comparison may be correctly used in further calculations.
Table VIII

Results of Consistency Test for Matrix

\begin{tabular}{|l|c|c|c|c|}
\hline & $\lambda_{\max }$ & CI & RI & CR \\
\hline F & 4.2619 & 0.0873 & 0.89 & $9.81 \%$ \\
\hline F1 & 3.0192 & 0.0096 & 0.52 & $1.84 \%$ \\
\hline F2 & 3.0744 & 0.0372 & 0.52 & $7.15 \%$ \\
\hline F3 & 3.0192 & 0.0096 & 0.52 & $1.84 \%$ \\
\hline F4 & 3.0192 & 0.0096 & 0.52 & $1.84 \%$ \\
\hline
\end{tabular}

D. Step 4: Weight calculation for risk factors.

This step includes the weight calculation of factors, where for this purpose, in accordance to the Chang FAHP method, Fuzzy Extend Analysis [11] is used, the main idea of which is to calculate the crisp weights from fuzzy comparison matrices. Necessary for calculation formulas are listed in part V.

Calculation results of equation (9) in matrix of pairwise comparisons are included in Table II and are represented as follows:

$$
\begin{array}{ll}
S_{F 1}=(2.50,3 \cdot 07,4.50), & S_{F 2}=(4 \cdot 00,5 \cdot 50,7 \cdot 00), \\
S_{F 3}=(3.50,4.67,6.00), & S_{F 4}=(3 \cdot 90,4 \cdot 67,5 \cdot 67) .
\end{array}
$$

\section{E. Step 5: Individual preferences aggregation.}

Then, in compliance with the FAHP methodology, the crisp weight from the fuzzy triangular weights should be determined. For this purpose, D. Chang [11] offered to use a concept of the fuzzy numbers comparison in order to calculate crisp values from the fuzzy weights values. Next, for each fuzzy weight, a pair wise comparison with the other fuzzy weights are conducted (using equation (12)), and the degree of possibility of being greater than these fuzzy weights are obtained. The minimum of these possibilities are used as the overall score for each factor.

After applying the equation (12) towards results obtained at the previous stage, the following values were got:

$$
\begin{array}{ll}
V\left(S_{F 1} \geq S_{F 2}\right)=0.53, & V\left(S_{F 1} \geq S_{F 3}\right)=0.66, \\
V\left(S_{F 1} \geq S_{F 4}\right)=0.64, & V\left(S_{F 2} \geq S_{F 1}\right)=1.00, \\
V\left(S_{F 2} \geq S_{F 3}\right)=1.00, & V\left(S_{F 2} \geq S_{F 4}\right)=1.00, \\
V\left(S_{F 3} \geq S_{F 1}\right)=1.00, & V\left(S_{F 3} \geq S_{F 2}\right)=0.85, \\
V\left(S_{F 3} \geq S_{F 4}\right)=1.00, & V\left(S_{F 4} \geq S_{F 1}\right)=1.00, \\
V\left(S_{F 4} \geq S_{F 2}\right)=0.84, & V\left(S_{F 4} \geq S_{F 3}\right)=1.00 .
\end{array}
$$

Finally, these scores were normalized (using equation 13), and the corresponding scores of the 4 categories of risk factors obtained:

$$
W_{F}=(0.164,0.312,0.264,0.260)
$$

Similarly using extent analysis method, the weight vectors of the risk factors $\left(F_{1}-F_{4}\right)$ were obtained:

$$
\begin{aligned}
& W_{F 1}=(0.343,0.450,0.207), \\
& W_{F 2}=(0.376,0.284,0.341), \\
& W_{F 3}=(0.207,0.343,0.450), \\
& W_{F 4}=(0.450,0.343,0.207) .
\end{aligned}
$$




\section{F. Step 6: Final risk factors ranking.}

On the last stage the risk factors ranking was done. Ranking is implemented on the basis of the overall weights' value, which is equal to correlation of the local weight to its "farther factor" weight. Weights of the category importance and the risk factors are shown in Table IX, as well as are illustrated by the diagram in Fig. 3 .

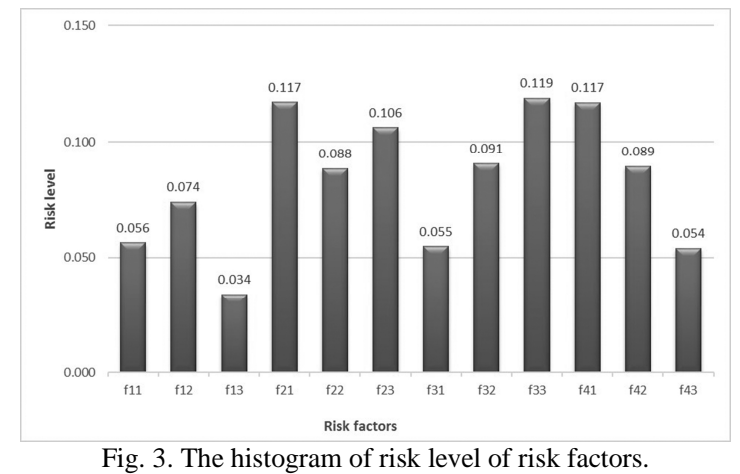

Fig. 3. The histogram of risk level of risk factors.

Table IX

Weight Table For Risk Factors

\begin{tabular}{|c|c|c|c|c|}
\hline \multirow{2}{*}{$\begin{array}{c}\text { Risk } \\
\text { categories }\end{array}$} & $\begin{array}{c}\text { Local } \\
\text { weight }\end{array}$ & $\begin{array}{c}\text { Risk } \\
\text { factor }\end{array}$ & $\begin{array}{c}\text { Local } \\
\text { weight }\end{array}$ & $\begin{array}{c}\text { Overall } \\
\text { weight }\end{array}$ \\
\hline \multirow{3}{*}{$F_{1}$} & \multirow{3}{*}{0,164} & $f_{11}$ & 0.343 & 0.056 \\
\cline { 3 - 5 } & & $f_{12}$ & 0.450 & 0.074 \\
\cline { 3 - 5 } & \multirow{3}{*}{$F_{2}$} & $f_{13}$ & 0.207 & 0.034 \\
\hline \multirow{3}{*}{$F_{3}$} & \multirow{3}{*}{0,312} & $f_{21}$ & 0.376 & 0.117 \\
\cline { 3 - 5 } & \multirow{3}{*}{0,264} & $f_{22}$ & 0.284 & 0.088 \\
\cline { 3 - 5 } & & $f_{23}$ & 0.341 & 0.106 \\
\cline { 3 - 5 } & \multirow{3}{*}{$F_{4}$} & $f_{31}$ & 0.207 & 0.055 \\
\cline { 3 - 5 } & \multirow{2}{*}{0,260} & $f_{32}$ & 0.343 & 0.091 \\
\cline { 3 - 5 } & & $f_{33}$ & 0.450 & 0.119 \\
\cline { 3 - 5 } & & $f_{41}$ & 0.450 & 0.117 \\
\hline \multirow{2}{*}{} & & $f_{43}$ & 0.343 & 0.089 \\
\hline
\end{tabular}

\section{CONCLUSION AND FUTURE RESEARCH}

Characteristics advantages and disadvantages of the most frequently used and popular FAHP method have been investigated in the present paper. After having revised the methods, a decision to use the Chang FAHP method in the analysis of ecological risk in case of spread of invasive species in this paper was used. In accordance with the Chang FAHP method the hierarchy and regularity of factors were defined on the basis of experts' evaluations. It led to the calculation of the factors weights, reflecting the importance of each factor and categories of the risk factors, using the complex FAHP method for the risk assessment. Then the quantitative analysis of the risk factors was done. Finally, factors were ranked in accordance with their influence on the overall level of risk and the determinative risk factors, influencing the ecological risk in case of spread of invasive species, were defined.
It is shown by the application in definite cases that the risk assessment Chang FAHP method is easy and effective in engineering, which can provide technical support in the ecological risk assessment process. Also, the application of the FAHP method allows making a complex algorithm of analysis more affordable in order to obtain the risk assessment given an incomplete and reduced input data. The methodology can be used by government since it is a method that allows the evaluation of the risk level and also to see whether the safety measurements are suitable. This application can be used as a preliminary risk assessment tool, being able to highlight critical situations and the need for more indepth and complete analysis. Also it can be used to help to take a thoughtful decision for reducing the risk level.

In future research is planned to analyze the ecological risk by using the van Laarhoven and Pedrycz and the Buckley FAHP methods in order to compare and to substantiate the results.

\section{REFERENCES}

[1] D.K Asante-Duah, Hazardous waste risk assessment, Lewis Publishers, Ann Arbor pp. 384, 1993.

[2] T.L. Saaty, "A scaling method for priorities in hierarchical structure," J Math Psychol, vol. 15, pp.234-281, 1977.

[3] T.L. Saaty, The analytic hierarchy process, McGraw-Hill, New York, 1980.

[4] T. L. Saaty, Decision Making with Dependence and Feedback. The Analytic Network Process. RWC Publication, Pittsburg, 1996.

[5] van Laarhoven, W Pedrycz, "A fuzzy extension of Saaty's priority theory," Fuzzy Sets and Systems, vol. 11, pp. 199227, 1983.

[6] C. G. E. Boender, J. G. de Grann, F. A. Lootsma, "Multicriteria decision analysis with fuzzy pairwise comparison," Fuzzy Sets and Systems, vol. 29, pp. 133-143, Jan. 1989.

[7] Y.-M. Wang, T. M. S. Elhag, Z. Hua, "A modified fuzzy logarithmic least squares method for fuzzy analytic hierarchy process," Fuzzy Sets and Systems, vol. 157, pp. 3055-3071. Dec. 2006.

[8] J. J. Buckley, "Fuzzy hierarchical analysis," Fuzzy Sets and Systems, vol. 17, pp. 233-247, 1985.

[9] M. B. Ayhan "A fuzzy AHP approach for supplier selection problem: a case study in agearmotor company," International Journal of Managing Value and Supply Chains, vol. 4, Sept. 2013.

[10] R. Csutora, J.J. Buckley, "Fuzzy hierarchical analysis: The Lamda-Max method," Fuzzy Sets and Systems, vol. 120, pp. 181-195, 2001.

[11] D. Chang, "Applications of the extent analysis method on fuzzy AHP," European Journal of Operational Research, vol. 95, pp. 649-655, 1996.

[12] M. Enea, T. Piazza, "Project selection by constrained fuzzy AHP," Fuzzy Optim. Decis. Making, vol. 3, pp. 39-62, 2004.

[13] H. Eunnyeong, K. Jinsoo, B. Kyung-Jin, "Analysis of the assessment factors for renewable energy dissemination program evaluation using fuzzy AHP," Renewable and Sustainable Energy Reviews, vol. 14, pp. 2214-2220, Oct. 2010.

[14] O. Taylana, A. O. Bafailb, R.M.S. Abdulaala, M. R. Kablia, "Construction projects selection and risk assessment by fuzzy AHP and fuzzy TOPSIS methodologies," Applied Soft Computing, vol. 17 , pp. 105-116, April 2014. 